\title{
A IMPORTÂNCIA DAS INUNDAÇÕES NA EXPANSÃO DA ESQUISTOSSOMOSE MANSONI (1)
}

\author{
Alberto da Silva RAMOS (2) \\ José de Toledo PIZA (3) \\ Euclides FRóES (4)
}

Ramos, A. da S.; Piza, J. de T. \& Fróes, E. - A importância das inundações na expansão da esquistossomose mansoni. Rev. Saúde públ., S. Paulo, 4:1-5, jun. 1970 .

RESUMo - Faz-se alusão à interferência das inundações na vida dos planorbídeos, quer contribuindo para a destruição de seus criadouros nas águas naturais e sistemas de irrigação, quer favorecendo sua proliferação e dispersão. Foram analisados os efeitos das enchentes e uma de suas conseqüências, que é a exacerbação da esquistossomose em focos antigos e o surgimento de novos. Foi relatada a ocorrência verificada em São José dos Campos, Estado de São Paulo, onde se deu o agravamento da parasitose em dois focos antigos, após as enchentes do Rio Paraíba e seus afluentes.

E conhecido o papel que desempenham as inundações na vida dos moluscos transmis. sores da esquistossomose; se de um lado podem contribuir para a destruição dos seus criadouros alterando as características ecológicas não só nas águas naturais mas também nos sistemas de irrigação, algumas vêzes facilitam a sua prolifera. ção e dispersão em virtude de condições favoráveis surgidas em dado local.

Determinam as enchentes a formação de lagoas e alagadiços nas depressões das margens dos cursos d'água, que irão posteriormente constituir criadoros adicionais de moluscos transmissores nas zonas endêmicas; causam o transbordamento dos canais de irrigação, trazendo à superfície os caramujos e espalhando-os por tôda a área cultivada e seus arredores; desorganizam sistemas de lançamento de esgôtos domésticos em zonas de várzeas, o que vai poluir as águas e conseqüentemente incrementar a proliferação dos planorbideos, facilitando maiores possibilidades de

Recebido para publicação em 17-10-1969

(1) Da Campanha de Combate à Esquistossomose (CACESQ), em colaboração com a Cadeira de Parasitologia da Escola Paulista de Medicina - São Paulo, S.P., Brasil. Apresentado na sessão do dia 4-8-1969, do Departamento de Higiene e Medicina Tropical da Associação Paulista de Medicina.

(2) Da Escola Paulista de Medicina, comissionado junto à Secretaria da Saúde Pública CACESQ - São Paulo, S.P., Brasil.

(3) Do Conselho Técnico da CACESQ - São Paulo, S.P., Brasil.

(4) Do Centro de Saúde de São José dos Campos, Est. de São Paulo, Brasil. 
RAMOS, A. da S.; PIZA, J. de T. \& FROES, E. - A importância das inundaçôes na expansão da esquistossomose mansoni. Rev. Saúde puibl., S. Paulo, 4:1-5, jun. 1970.

se infectarem pelo trematódeo; concorrem ainda para a dispersão dos moluscos vetores, que são transportados a grandes distâncias pelas touceiras de plantas aquáticas arrancadas pela violência das águas. Uma de suas conseqüências é a exacerbação da esquistossomose em focos antigos e o surgimento de novos, que marcam a expansão da endemia nas áreas onde se apresentam bem separadas as estações sêcas e chuvosas, o que tem sido observado no Estado de São Paulo em várias localidades (PizA et al. ${ }^{1}$, 1959, Rodrigues \& FERREIRA ${ }^{3}$, 1967, Ramos et al. ${ }^{2}, 1969$ ).

Além dêstes resultados podem determinar o aparecimento de um nôvo aspecto nas zonas onde a esquistossomose se manifesta em focos esparsos, o que vem confirmar a idéia segundo a qual a epidemiologia desta parasitose apresenta características de ordem local.

A finalidade destas notas é relatar a ocorrência verificada em dois locais da cidade de São José dos Campos, em fevereiro de 1967 , destacando as conseqüências das inundações ali verificadas. $\mathrm{Na}$ zona baixa do sub-distrito de Santana, existe um foco da endemia, que vinha sendo controlado. Uma enchente de grandes proporçóes determinou o transbordamento do Rio Paraíba, cujas águas ficaram parcialmente represadas, formando espécie de bacia, onde era lançado o produto do emissário de esgotos rompido pouco acima daquele local. A água recobriu uma rua que dava acesso a uma vila (Vila Cristina) situada em ponto elevado do terreno, bem junto à margem do rio, que ficou quase separada da cidade, o que obrigava os moradores a atravessar uma lâmina de água de 30 a $40 \mathrm{~cm}$, infestada por caramujos da espécie $B$. $t e$ nagophila, cujo exame revelou um certo número parasitada pelo Schistosoma mansoni. Em algumas casas inundadas também, foram coletados exemplares dêstes planorbídeos.

Naquele local a vegetação abundante, representada por gramíneas e onde não faltavam plantas aquáticas Eichhornia crassipes (aguapé) e Eichhornia diversifolia (chapéu de sapo) mais a água poluída pelos produtos do emissário de esgotos rompido em conseqüência da inundação, propiciaram condiçốes ecológicas para a proliferação em larga escala da espécie Biomphalaria tenagophila.

Outro ponto da cidade, no bairro do Lavapés, cortado pelo córrego do mesmo nome, foi também atingido pelas enchentes. Este córrego, que recebe o lançamento de esgotos das casas localizadas em grande parte de seu percursa, com a inundação, espraiou-se pela zona baixa, onde manteve a água com pequena profundidade, o que permitia a freqüência de crianças para seus folguedos. Ali também houve brusco aumento na proliferação dos moluscos e exacerbação do foco descoberto em 1962.

A conseqüência dêste episôdio foi o registro de casos novos da parasitose algum tempo após, revelados pelo censo coprológico.

\section{MATERIAL E METODOS}

Os locais pesquisados foram Vila Cristina, à margem do Rio Paraîba, e o bairro do Lavapés.

$\mathrm{Na}$ ocasião das enchentes foram efetuadas coletas de planorbídeos, inoculaçőes de camundongos albinos (Mus mus) em laboratório com cercárias obtidas de exemplares de Biomphalaria tenagophila colhidos naqueles pontos e também exposição de um lote dêstes animais à ação das cercárias "in natura", justamente no local de passagem obrigatória dos moradores da Vila Cristina pela rua Claudino Prisco.

Dois meses após a ocorrência foram repetidos censos coproscópicos nas populações daqueles locais, afim de se estabelecer comparação com os resultados anteriormente obtidos. Os exames para a pesquisa de ovos da Schistossoma mansoni nas amostras de fezes foram realizados no 
RAMOS, A. da S.; PIZA, J. de T. \& FRóES, E. - A importância das inundações na expansão da esquistossomose mansoni. Rev. Saúde puibl., S. Paulo, 4:1-5, jun. 1970.

laboratório do Centro de Saúde de São José dos Campos, enquanto que os exames de planorbídeos, inoculações de camundongos e observações sôbre o parasita após necropsia, foram efetuados no laboratório da Cadeira de Parasitologia da Escola Paulista de Medicina, em São Paulo.

Os métodos laboratoriais empregados, bem como os utilizados no campo já fo. ram referidos em trabalhos anteriores. 1,2

\section{R E S U I T A D O S}

Os resultados referem-se tão sòmente às observações realizadas no período de março a agôsto de 1967, em Vila Cristina e adjacências (subdistrito de Santana) e no bairro de Lavapés (subdistrito de São. José dos Campos).

A Tabela 1 mostra os resultados obtidos no censo coprológico realizado em Vila Cristina e adjacências e no bairro de Lavapés, com uma única amostra de fezes.

Pelos resultados obtidos com exame de planorbídeos podemos verificar na Tabela 2 que dos 761 exemplares examinados, 42 foram encontrados parasitados pelo trematódeo, com o índice de infecção natural de 5,7\%.

Foram inoculados camundongos albinos: (Mus mus) com cercárias eliminadas pelos exemplares de $B$. tenagophila, colhidos na Vila Cristina. As cercárias utilizadas. eram obtidas de lotes de cinco moluscos.

T A B E L A 1

Resultados obtidos no censo coprologico com uma única amostra de fezes (método de Hoffman, Pons e Janer)

\begin{tabular}{l|c|c|c}
\hline \multicolumn{1}{c|}{ Local } & $\begin{array}{c}\text { amostras } \\
\text { examinadas }\end{array}$ & positivos & $\%$ \\
\hline Vila Cristina & 464 & 21 & 4,5 \\
Adjacências da Vila Cristina & 548 & 10 & 1,8 \\
Bairro do Lavapés & 498 & 53 & 10,9 \\
\hline T o t a l & 1.510 & 53 & \\
\hline
\end{tabular}

T A B E L A 2

Resultados obtidos com exame de planorbideos (Biomphalaria tenagophila)

\begin{tabular}{|c|c|c|c|}
\hline Local & $\begin{array}{l}\text { exemplares } \\
\text { examinados }\end{array}$ & $\begin{array}{l}\text { parasitados } \\
\text { por } \\
\text { S. mansoni }\end{array}$ & $\begin{array}{c}\text { fndices } \\
\text { de infecção } \\
\text { natural }\end{array}$ \\
\hline \multicolumn{4}{|c|}{ Vila Cristina e adjacências } \\
\hline Lote 1 & 53 & 6 & $11,3 \%$ \\
\hline Lote 2 & 208 & 12 & $5,7 \%$ \\
\hline Lote 3 & 86 & 1 & $1,1 \%$ \\
\hline Lote 4 & 229 & 12 & $5,2 \%$ \\
\hline Lote 5 & 162 & 9 & $5,5 \%$ \\
\hline \multicolumn{4}{|l|}{ Bairro do Lavapés } \\
\hline Lote 1 & 23 & 2 & $8,7 \%$ \\
\hline$T \circ t$ a 1 & 761 & 42 & $37,5 \%$ \\
\hline
\end{tabular}


RAMOS, A. da S.; PIZA, J. de T. \& FRóES, E. - A importância das inundações na expansão da esquistossomose mansoni. Rev. Saúde pübl., S. Paulo, 4:1-5, jun. 1970.

Quatro lotes de camundongos albinos, pesando de 18 a $20 \mathrm{~g}$, foram utilizados na experiência. 0 tempo de exposição foi de $1 / 2 \mathrm{~h}$. A temperatura do ambiente era de $24^{\circ}$, sendo cem o número aproximado de cercárias por camundongo.

$\begin{array}{cccc}\text { Data } & \text { Lotes } & \begin{array}{c}\text { N.o de camun- } \\ \text { dongos } \\ \text { inoculados }\end{array} & \begin{array}{c}\text { Infectados } \\ \text { pelo }\end{array} \\ 13 / 3 & 1 & 5 & 5 \\ 14 / 3 & 2 & 5 & 5 \\ 21 / 3 & 3 & 7 & 6 \\ 28 / 3 & 4 & 10 & 10\end{array}$

Camundongos albinos expostos "in natura" no foco de Vila Cristina:

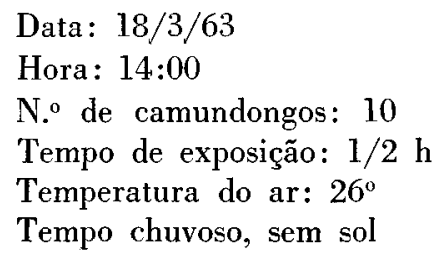

A necrópsia realizada em 9 animais, após 50 dias, revelou estarem 6 parasitados por vermes adultos, machos e fêmeas. Um camundongo morreu no segundo dia. 0 número de esquistossomos recuperados variou de 1 a 4 em cada camundongo, com a média de 2,8 .

\section{I S C U S S $\AA$ O}

A Vila Cristina é um conjunto de casas modestas, construídas sem os requisitos de higiene, não dispondo de abaste. cimento de água nem rêde de esgotos.

Os censos coprológicos ali realizados, desde 1965 a dezembro de 1966, pelo Centro de Saúde de São José dos Campos, revelaram a existência de três casos autóctones de esquistossomore. ${ }^{(1)}$
Após a ocorrência das inundações em fevereiro de 1967, nôvo censo coprológico efetuado nas mesmas proporções, demonstrou a existência de 21 casos seguramente autóctones daquele local.

A população, obrigada ao contato com a água contaminada pelas cercárias, foi atingida pela helmintose, que recrudesceu em conseqüência das novas condições surgidas com a inundação. Esta foi, sem dúvida, a responsável pela brusca proliferação dos caramujos que, provàvelmente, se tornaram expostos à ação dos miracídeos liberados nos esgotos lançados naquele ponto.

Quanto ao bairro do Lavapés, onde havia sido registrados 11 casos autóctones, de 1962 até dezembro de 1966, após a ocorrência das inundações, o censo coproscópico revelou 22 casos novos de pessoas que ali adquiriram a infecção ${ }^{(2)}$.

As percentagens de infecção obtidas no censo coprológico da Vila Cristina e Bairro do Lavapés, de $4,5 \%$ e $4,6 \%$ respectivamente, foram muito mais elevadas do que as observadas até então em outros focos do município.

No que se refere ao molusco vetor, as enchentes propiciaram maior proliferação e mais facilidade de se infectarem. As taxas de infecção natural observadas não foram tão elevadas, porém significativas se considerarmos o grande número de ca. ramujos disseminados na grande massa li. quida.

A verificação do grau de contaminação das águas pelas cercárias através da exposição de camundongos albinos foi útil para comprovar que exatamente naquela rua de passagem obrigatória dos moradores de Vila Cristina, os camundongos contrairam a infecção. Serviu esta obsevação, ao estabelecimento e orientação das me. didas de saneamento quando de sua exe. cução.

(1) Dados inéditos.

(2) Censo coproscópico realizado pelo Centro de Saúde de São José dos Campos — dados inéditos. 
RAMOS, A. da S.; PIZA, J. de T. \& FROES, E. - A importância das inundações na expansão da esquistossomose mansoni. Rev. Saúde públ., S. Paulo, 4:1-5, jun. 1970.

\section{O N C L U S O E S}

1 - As enchentes podem concorrer para a expansão da esquistossomose propiciando condições para a instalação de novos focos.

2 - Foi comprovada a exacerbação de focos da parasitose, como resultante das condiçoes locais surgidas com as inundações.

3 - Nas observações realizadas em zona baixa, de várzeas, foi verificado incremento na proliferação de Biomphalaria tenagophila por ocasião das enchentes.

4 - Na construção de rêdes de esgotos, em zonas sujeitas a inundações, deve ser levado em conta a possibilidade do rompimento do emissário em virtude do represamento do material no interior da tubulaŗão, aumentando a sua pressão.

Ramos, A. da S.; PIzA, J. de T. \& Fróes, E. - [The importance role of floods in spreading schistosomiasis mansoni]. Rev. Saúde públ., S. Paulo, 4:1-5, jun. 1970.

Summary - The interference of the floods in the planorbideos' life, whether contributing to the destruction of the focus in natural waters and irrigation systems, or in favouring their proliferation and dispersion of them, is mentioned. The effects of the flood and one of its consequences is the exacerbation of schistosomiasis in old focus and the appearing of new ones, are analysed. The occurency verified in the county of "São José dos Campos", State of São Paulo, Brazil, where the parasitosis increased in two old foci after the overflowing of the Paraiba river and its tributaries, is reported.

A G R A D E C I M E T O S

Aos srs. Jonas de Almeida, do Centro de Saúde de São José dos Campos, Miguel Baena, da Delegacia de Saúde de Taubaté, Mário Nogueira, Geraldo Teixeira Leão e d. Noemi Bierrenbach de Lima, do Serviço de Documentação da Secretaria da Saúde, pela colaboração.

\section{REFERENCIAS BIBLIOGRAFICAS}

1. PIZA, J. de T. et al. - A esquistossomose no Vale do Paraiba (Estado de São Paulo - Brasil). Observações sôbre a doenca em alguns de seus municípios e a fauna planorbídica da região. Rev. Inst. A. Lutz, 19:97-143, 1959.

2. RAMOS, A. da S. et al. - Focos ativos de esquistossomose mansoni no Vale do Ribeira, Estado de São Paulo, Brasil. Rev. Saúde públ., S. Paulo, 3:59-65, jun. 1969.

3. RODRIGUES, D. C. \& FERREIRA, C. S. - Esquistossomose mansoni nos municipios de Santo André e São Bernardo do Campo (SP, Brasil): encontro de casos humanos autóctones e de exemplares de Biomphalaria tenagophila naturalmente infestados pelo Schistosoma mansoni |Nota prévial. Rev. paul. Med., 71:48, jul. 1967. 